\title{
Tracing fish farm waste in the northern shrimp Pandalus borealis (Krøyer, 1838) using lipid biomarkers
}

\author{
Siri Aaserud Olsen ${ }^{1, *}$, Arne Ervik ${ }^{1}$, Otto Grahl-Nielsen ${ }^{2}$ \\ ${ }^{1}$ Institute of Marine Research, 5817 Bergen, Norway \\ ${ }^{2}$ Department of Chemistry, University of Bergen, 5007 Bergen, Norway
}

\begin{abstract}
A large amount of organic effluents are released annually from coastal fish farming locations primarily in the form of faeces that settle to the seabed, where they become a substantial food source for benthic communities. The inclusion of marine and vegetable oils as sources of lipids in salmon feed has resulted in a fatty acid (FA) composition that differs markedly from marine-derived material, and thus they can be used as an efficient tracer for the distribution of fish farm waste in both sediments and fish. To obtain a better understanding of the flux of organic fish farm waste through the benthic food web, we sampled northern shrimp Pandalus borealis at fish farming and reference locations in 4 regions along the Norwegian coast. Analyses of the FA compositions of muscular tissue demonstrated that shrimp collected within $800 \mathrm{~m}$ from fish farms had a higher content of the vegetable-derived FAs 18:2n6 (linoleic acid) and 18:3n3 ( $\alpha$-linolenic acid) and the marine FAs 20:1n9 and 22:1n11, compared with shrimp collected from reference locations. This difference in specific FA contents allowed us to separate shrimp collected at fish farming locations from those collected at reference locations. Our results demonstrate that shrimp within the distribution range of fish farms can incorporate organic fish farm waste into part of their diet, either directly through the consumption of waste feed and faeces or indirectly by feeding on influenced infauna.
\end{abstract}

KEY WORDS: Aquaculture $\cdot$ Fish farm effluent $\cdot$ Fatty acids $\cdot$ Benthic food web

\section{INTRODUCTION}

In 2009, aquaculture contributed close to $40 \%$ of the world fisheries (55 million $\mathrm{t}$ ), making it an important industry for supplying the increased global demand for protein (FAO 2010). In salmonid farming, $\sim 2 \%$ of the fish feed is uneaten and released from the net pens (Cho \& Bureau 1998, Dempster et al. 2009), and it is estimated that 20 to $30 \%$ of the ingested feed is released as faecal waste (Bureau et al. 2003, Overland et al. 2009). This results in a substantial amount of organic waste material being released to the waters close to a fish farm. Whilst waste feed may be eaten by aggregated wild fish (Carss 1990, Dempster et al. 2009), the remainder of uneaten waste will be released to the recipient environment where it will settle to the seabed and become available to the benthic fauna and potentially cause dramatic changes in benthic fauna species richness, biomass and abundance (Brown et al. 1987, Kutti et al. 2007b).

The Norwegian salmonid production is an important contributor to the global aquaculture industry, producing $\sim 1$ million t of Atlantic salmon Salmo salar and rainbow trout Oncorhynchus mykiss in 2010 (NDF 2010). The production is distributed at more than 1000 locations along the entire coastline of Norway with a total feed consumption of 1.3 million $t$ in 2010 (NDF 2010). As a large proportion of the fish 
farms are located in deep fjords where benthic production is food limited (Pearson 1980), organic waste material to the recipient environment may contribute considerably to the food supply for the benthic fauna community. Investigations at a deep fish farm location in Norway by Kutti et al. (2007b) revealed a 9 -fold increase in the carbon-flux to the seabed followed by 10-fold and 35-fold increases in infauna abundance and biomass, respectively, compared with a reference location, i.e. one not affected by fish farms.

Norwegian aquaculture is based on the ecosystem approach (Anonymous 2009), which implies that the trophic structure and main pathways of energy flow through the marine systems must not be dramatically altered. It is crucial to understand how increased benthic production caused by organic wastes from fish farms influences the demersal food web. These interactions are also interesting from an economic point of view as the inshore fisheries are significant and provide a livelihood for coastal residents.

Traditionally, fish meal and fish oil have been the most important components of salmonid feeds. However, owing to the heavy increase in the global aquaculture production, ingredients of vegetable origin have been included and now comprise about $50 \%$ of the feed (Skretting Norway 2010). In addition to the long-chained polyunsaturated fatty acid (FA) (LCPUFA) like 20:5n-3 and 22:6n-3 (eicosapentaenoic acid [EPA] and docosahexaenoic acid [DHA], respectively) from the marine lipids, salmon feeds are also enriched in 18 carbon FAs typical of vegetable oils, such as 18:1n9, 18:2n6 and 18:3n3 (oleic, linoleic and $\alpha$-linolenic acid, respectively) (Gunstone et al. 1994). The inclusion of vegetable oils reduces the concentration of highly unsaturated n-3 FA (n-3 HUFA) in the feeds, which, as a general consequence, results in a lower n3:n6 ratio in the muscle tissue of farmed fish (Bell et al. 2002, 2003, Blanchet et al. 2005). Consequently, the composition of feeds has a FA profile that differs from the natural marine-derived material and can be used as a tracer to determine the distribution of organic fish farm waste into both sediments (Samuelsen et al. 1988, Johnsen et al. 1993, Henderson et al. 1997), zooplankton (Fernandez-Jover et al. 2009) and fish (Skog et al. 2003, Fernandez-Jover et al. 2011). The distribution of fish farm waste into benthic species is on the other hand, poorly investigated.

The northern shrimp Pandalus borealis is a common northern Atlantic epibenthic species inhabiting Norwegian coastal waters and has an important economic value for coastal fisheries; $2000 \mathrm{t}$ were landed in 2008 (NDF 2008). Shrimp are demersal opportunistic omnivores and feed on organisms such as polychaetes, smaller crustaceans, detritus, shell fragments and echinoderms (see tables and references in Bergström 2000). Despite being a benthic feeder, they undertake vertical migrations at night to feed on macroplankton. Northern shrimp is considered a key species and an important link between the benthic and higher trophic levels, as it is an important food source for several fish species, particularly gadoids, as well as for larger crustaceans, squid and seals (Shumway et al. 1985, Parsons 2005). Furthermore, high abundances of shrimp are normally found to be associated with high organic sediment content (Wigley 1960, Ramseier et al. 2000); thus, they potentially can be used as an indicator organism for aquaculture-derived effluents (Olsen et al. 2009).

In a previous study we conducted an experiment where shrimp were fed salmon feed pellets (Olsen et al. 2009). The results showed that the FA content and composition are suitable biomarkers for tracing fish farm organic waste to shrimp. Modifications were visible after $10 \mathrm{~d}$, and FA 18:2n6 proved to be a tracer in fish-farm-influenced shrimp, as it is documented in fish (Skog et al. 2003, FernandezJover et al. 2007, 2011). To validate these tracers, we sampled shrimp from fish farms along the Norwegian coast and compared the FA content and composition with shrimp collected at locations with no farm activity. These results could increase our knowledge on the flux of organic fish farm waste through the local food web and how the fish waste can represent a food source for adjacent demersal fauna populations. Furthermore, the results of this study could be used to establish northern shrimp as an indicator species for aquaculture-derived effluents for coastal management of aquaculture in the northern Atlantic Ocean.

\section{MATERIALS AND METHODS}

\section{Collection of material}

Pandalus borealis were collected from 4 regions along the Norwegian coast (north, middle, west and south) during 2003 and 2004 (Fig. 1, Table 1). At each of the 7 farm locations and 5 reference locations, 20 adult specimens were sampled by trawling, immediately frozen at $-20^{\circ} \mathrm{C}$ and sent to the Institute of Chemistry, University of Bergen, where they were analysed within 1 to $6 \mathrm{wk}$. Trawling was performed as close to the farm as topography and mooring 

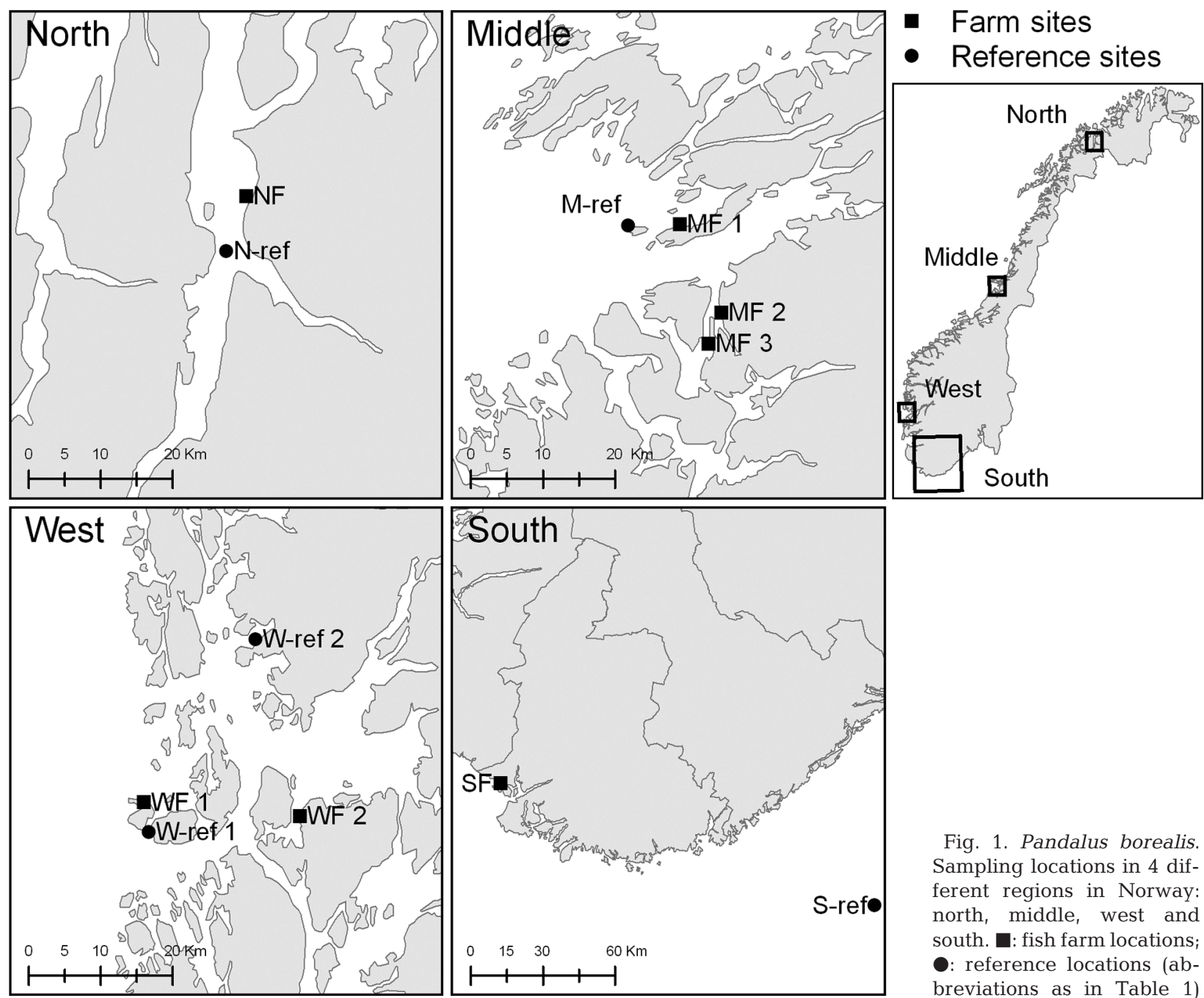

Fig. 1. Pandalus borealis. Sampling locations in 4 different regions in Norway: north, middle, west and

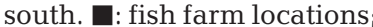
-: reference locations (abbreviations as in Table 1)

Table 1. Sampling locations and farm management details. Biomass (metric tons, $\mathrm{t}$ ), feed consumption $\left(\mathrm{t} \mathrm{d}^{-1}\right.$ ), and stage of the production cycle (typical duration: $18 \mathrm{mo}$ ) at the time (month and year) of sampling. Distance to the nearest fish cage (for farm sites) or the nearest fish farm (for reference sites) are indicated

\begin{tabular}{|c|c|c|c|c|c|c|c|}
\hline \multirow{2}{*}{$\begin{array}{l}\text { Location } \\
\text { name }\end{array}$} & \multirow[t]{2}{*}{ Abbreviation } & \multirow{2}{*}{$\begin{array}{l}\text { Sample } \\
\text { time }\end{array}$} & \multirow{2}{*}{$\begin{array}{c}\text { Biomass } \\
\text { (t) }\end{array}$} & \multirow{2}{*}{$\begin{array}{c}\text { Feed } \\
\text { consumption } \\
\left(\mathrm{t} \mathrm{d}^{-1}\right)\end{array}$} & \multirow[t]{2}{*}{ Management comments } & \multicolumn{2}{|c|}{-Distance to } \\
\hline & & & & & & $\begin{array}{l}\text { Fish cage } \\
(\mathrm{m})\end{array}$ & $\begin{array}{c}\text { Fish farm } \\
\quad(\mathrm{km})\end{array}$ \\
\hline North Farm & NF & Jun 2004 & 134 & 1.8 & Early in production cycle & $750-2200$ & \\
\hline North ref & N-ref & Jun 2004 & & & & & 7.2 \\
\hline Middle Farm 1 & MF1 & Jun 2004 & 2375 & not known & Middle of production cycle & $800-1700$ & \\
\hline Middle Farm 2 & MF2 & Jun 2004 & 110 & 2 & Early in production cycle & $1000-3000$ & \\
\hline Middle Farm 3 & MF3 & Jun 2004 & 1200 & 9.5 & Middle of production cycle & $500-1400$ & \\
\hline Middle ref & M-ref & Jun 2004 & & & & & 4 \\
\hline West Farm 1 & WF1 & Jun 2004 & 444 & 5.2 & Middle of production cycle & $400-1200$ & \\
\hline West Farm 2 & WF2 & Nov 2003 & 690 & 4.2 & Middle of production cycle & $0-500$ & \\
\hline & & Feb 2004 & 1240 & 4.4 & Middle of production cycle & $0-500$ & \\
\hline West ref 1 & W-ref1 & Jun 2004 & & & & & 4.5 \\
\hline West ref 2 & W-ref2 & Nov 2003 & & & & & 10 \\
\hline & & Feb 2004 & & & & & 10 \\
\hline South Farm & $\mathrm{SF}$ & Jun 2004 & 1500 & 3.6 & Farm 1. End of production cycle & $500-2500$ & \\
\hline & & Jun 2004 & 1000 & 7.8 & Farm 2. End of production cycle & $500-2500$ & \\
\hline South ref & S-ref & Jun 2004 & & & & & 165 \\
\hline
\end{tabular}


allowed, between 0 and $3000 \mathrm{~m}$ from the nearest fish farm (Table 1), at depths between 140 and $265 \mathrm{~m}$. West Farm 2 (WF2) was moored at a single point, drifting along a north-south gradient with tides and currents, which made it possible to trawl in the actual 'footprint' of the farm (Kutti et al. 2007a,b). Feed pellets were collected from each farm on sampling day, except from 'Middle' where feed was obtained only from Middle Farm 1 (MF1). The reference locations were located from 4 to $10 \mathrm{~km}$ away from any farm activity (Fig. 1, Table 1), except the South reference site (S-ref), which was sampled in the Skagerrak, $165 \mathrm{~km}$ away from the farm location.

\section{Information of location and farm management}

Details on farm management, locations and abbreviations are listed in Table 1 . The farms in the west and south were well established and had production cycles for many years ( 1 production cycle $=1$ generation $=18 \mathrm{mo}$ ). The North Farm $(\mathrm{NF})$ had only produced 1 generation of Atlantic salmon, after which it remained empty for $2 \mathrm{yr}$, and then restarted production only a few weeks before our sampling. Also the middle farms were well established, although Middle Farm 2 (MF2) had just ended a 1 yr fallow period and was launching a new generation of fish at the time of our sampling. At WF2 and West reference site 2 (W-ref2), shrimp were sampled twice within 3 mo during the winter of 2003-2004, and these samples were treated separately. All other shrimp samples were collected from May to June. The South Farm (SF) shrimp were collected at a location between 2 farms of the same company that used the same feed.

\section{Sample preparation and gas chromatography}

Samples of shrimp muscle tissue from the dorsal abdomen were submitted to methanolysis and gas chromatography as described in Olsen et al. (2009), and the FA 19:0 was used as an internal standard. The detector signal was digitally recorded in the Atlas software (Thermo Labsystems) and peaks were identified by comparing them with a standard mixture and by using previous knowledge of relative retention times of FA methyl esters (FAMEs) and mass spectrometry. The peak areas of ca. 40 selected FAMEs that were between 14:0 and 24:1n9 were integrated and corrected by response factors. These corrected peak areas were then used for a multivariate analysis and to calculate the FA content. Peaks that contributed to $<0.2 \%$ were not included, as the low precision in the determination of the areas of their peaks contribute more noise than real information, which left us with 24 FAs to be used for analysis.

Total FA content, expressed as mg FA g ${ }^{-1}$ muscle tissue or feed material, was calculated from the total area of all 24 identified FAs in relation to the area of the internal standard. The relative content of each FA in the samples was calculated as a percentage of the total. Since environmental differences can influence the FA composition, samples collected from the different regions were treated separately.

\section{Statistical analysis}

To obtain a clear picture of the differences in the FA composition between shrimp collected close to fish farms and those from reference locations, samples were subjected to multivariate analysis by using the software package Sirius 6.5 (Kvalheim \& Karstang 1987). The relative amounts of the FAs were logarithmically transformed to avoid domination of the most abundant FAs. Principal component analyses (PCAs) were performed by positioning the samples in a 24-dimensional space described by the variables (FAs). New coordinates, principal components (PCs), were drawn through the centroid of the samples in such a manner that principal component 1 (PC1) expressed direction of the largest and principal component 2 (PC2), which is orthogonal to PC1, was the direction of the second largest variation among the samples. The original variables (FAs) were displayed together with the samples, resulting in a socalled biplot that visualizes the correlation between samples and FAs. FAs far from the origin contribute most to sample variation. In addition, samples close to an FA along a principal component contain relatively more of this FA than samples lying in the opposite direction.

The other statistical analyses were performed with SYSTAT version 10. One-way analyses of variance (ANOVAs) were run to find significant differences in FA composition, total FA content and the n3:n6 ratio between the shrimp samples within each region. Based on the PCA results, knowledge of FA content in fish feed oils and from literature, a set of FAs (18:2n6, 18:3n3, 18:1n9, 20:1n9 and 22:1n11) were considered to be potentially suitable FAs for fish farm waste, and these were tested by 1-way ANOVA and subsequent post hoc Tukey's test. Arcsine transformations were performed on the percent data before the testing. All data were checked for homogeneity 
of variance and normality by using residuals versus predicted values plot and Q-Q plots of residuals, respectively. Owing to multiple testing, a Bonferronitransformed, experiment-wise $\alpha=0.01$ was employed to reduce Type 1 error rates (Quinn \& Keough 2002). Dissimilarity rates ( $\mathrm{R}$ between 0 and 1 ) within each region were also calculated with analysis of similarities (ANOSIM) from the PRIMER package, where rates closer to 1 are more dissimilar.

\section{RESULTS}

The FA composition in feed pellets varied significantly between the various farms, Tables $2 \& 3$ (significance data not shown). The pellets from WF2 (2003) differed most from the others, and had higher levels of 18:2n6, 16:0 and 18:1n9 and lower levels of 20:1n9 and 22:1n11. Feed from the NF grouped with feed from WF2 (2004) and was distinct from the others, as it had higher values of $22: 5 n 3,16: 3 n 4$ and 18:3n 3 and lower values of 20:0. The remaining 3 feeds from all middle farms, WF1 and SF were fairly similar in FA composition.

Irrespective of the differences in FA composition among the pellets used at the different farms, the pellets as a group have very different FA composition from that of the shrimp (Fig. 2). This difference is, on the one hand, caused by the FAs indicated on the right side of the plot in Fig. 2, because FA levels, particularly the 2 long-chained monounsaturated 20:1n9 and 22:1n11, are higher in the pellets. On the other hand, the FAs indicated on the left side of the plot occur in lower levels in the pellets. This is seen in Tables 2 \& 3, i.e. 20:1n9 and 22:1n11 have relative amounts of around 1 to $2 \%$ in the shrimp tissue,

Table 2. Pandalus borealis. Relative amounts (percentage of total $\pm \mathrm{SD}$ ) and total amount of fatty acids $\left(\mathrm{mg} \mathrm{FA} \mathrm{g}^{-1} \pm \mathrm{SD}\right.$ bottom row) in the muscle tissue of northern shrimp collected from North and Middle fish farm and reference locations, and of fish feed pellets (shaded columns) used at the respective fish farms. Significant differences $(\mathrm{p}<0.01,1$-way ANOVA and Tukey's HSD test) in FA profiles of shrimp tissue are presented for variables marked $\left({ }^{*}\right)$; significantly different means within rows (within each region) are indicated by different letters in superscript

\begin{tabular}{|c|c|c|c|c|c|c|c|c|}
\hline $\begin{array}{l}\text { Fatty } \\
\text { acid }\end{array}$ & $\begin{array}{l}\text { North } \\
\text { Farm } \\
\mathrm{n}=20\end{array}$ & $\begin{array}{l}\text { North } \\
\text { reference } \\
\mathrm{n}=20\end{array}$ & $\begin{array}{l}\text { North } \\
\text { feed } \\
\mathrm{n}=4\end{array}$ & $\begin{array}{c}1 \\
\mathrm{n}=20\end{array}$ & $\begin{array}{c}\text { - Middle Farm } \\
2 \\
\mathrm{n}=20\end{array}$ & $\begin{array}{c}3 \\
\mathrm{n}=20\end{array}$ & $\begin{array}{l}\text { Middle } \\
\text { reference } \\
\mathrm{n}=20\end{array}$ & $\begin{array}{l}\text { Middle } \\
\text { feed } \\
\mathrm{n}=4\end{array}$ \\
\hline 14:0 & $2.01 \pm 0.28$ & $2.05 \pm 0.26$ & $5.74 \pm 0.02$ & $2.33 \pm 0.20$ & $2.02 \pm 0.16$ & $1.92 \pm 0.15$ & $2.23 \pm 0.30$ & $5.04 \pm 0.10$ \\
\hline iso $16: 0$ & $0.12 \pm 0.02$ & $0.12 \pm 0.02$ & $0.10 \pm 0.00$ & $0.19 \pm 0.03$ & $0.19 \pm 0.03$ & $0.15 \pm 0.04$ & $0.27 \pm 0.05$ & $0.12 \pm 0.01$ \\
\hline $16: 0$ & $19.87 \pm 0.63$ & $20.02 \pm 0.64$ & $16.41 \pm 0.06$ & $18.73 \pm 0.94$ & $18.82 \pm 0.93$ & $19.39 \pm 0.72$ & $18.14 \pm 0.84$ & $15.11 \pm 0.27$ \\
\hline $16: 1 \mathrm{n} 7$ & $6.54 \pm 0.60$ & $6.56 \pm 0.51$ & $6.32 \pm 0.04$ & $5.16 \pm 0.45$ & $5.59 \pm 0.59$ & $5.35 \pm 0.62$ & $6.31 \pm 0.45$ & $6.05 \pm 0.05$ \\
\hline $16: 2 \mathrm{n} 11$ & $0.38 \pm 0.03$ & $0.38 \pm 0.05$ & $0.34 \pm 0.00$ & $0.49 \pm 0.06$ & $0.62 \pm 0.08$ & $0.53 \pm 0.10$ & $0.77 \pm 0.21$ & $0.35 \pm 0.00$ \\
\hline $16: 2 \mathrm{n} 6$ & $0.23 \pm 0.04$ & $0.25 \pm 0.04$ & $0.09 \pm 0.00$ & $0.39 \pm 0.05$ & $0.41 \pm 0.06$ & $0.36 \pm 0.06$ & $0.51 \pm 0.13$ & $0.11 \pm 0.01$ \\
\hline $16: 3 n 4$ & $0.58 \pm 0.09$ & $0.61 \pm 0.07$ & $0.29 \pm 0.01$ & $0.88 \pm 0.07$ & $1.02 \pm 0.08$ & $1.00 \pm 0.12$ & $0.93 \pm 0.09$ & $0.18 \pm 0.01$ \\
\hline $16: 4 n 3$ & $0.57 \pm 0.06$ & $0.54 \pm 0.06$ & $0.30 \pm 0.02$ & $0.67 \pm 0.23$ & $0.85 \pm 0.11$ & $0.77 \pm 0.23$ & $0.64 \pm 0.11$ & $0.29 \pm 0.01$ \\
\hline $16: 4 \mathrm{n} 1$ & $0.32 \pm 0.05$ & $0.31 \pm 0.05$ & $0.02 \pm 0.00$ & $0.74 \pm 0.47$ & $0.85 \pm 0.10$ & $0.89 \pm 0.11$ & $0.62 \pm 0.14$ & $0.02 \pm 0.00$ \\
\hline $18: 0$ & $2.32 \pm 0.21$ & $2.56 \pm 0.25$ & $2.48 \pm 0.01$ & $2.94 \pm 0.21$ & $3.77 \pm 0.22$ & $3.74 \pm 0.24$ & $4.05 \pm 0.57$ & $2.82 \pm 0.12$ \\
\hline $18: 1 \mathrm{n} 9^{*}$ & $11.10 \pm 0.71$ & $10.51 \pm 0.97$ & $15.98 \pm 0.03$ & $11.67 \pm 2.25^{\mathrm{b}}$ & $10.05 \pm 0.84^{\mathrm{a}}$ & $10.03 \pm 0.69^{a}$ & $10.07 \pm 1.02^{\mathrm{a}}$ & $12.57 \pm 0.09$ \\
\hline $18: 1 \mathrm{n} 7$ & $7.12 \pm 0.29$ & $6.91 \pm 0.31$ & $2.91 \pm 0.00$ & $6.69 \pm 0.65$ & $7.32 \pm 0.38$ & $7.41 \pm 0.35$ & $7.20 \pm 0.36$ & $3.29 \pm 0.05$ \\
\hline $18: 1 \mathrm{n} 5$ & $0.44 \pm 0.03$ & $0.44 \pm 0.04$ & $0.35 \pm 0.00$ & $0.40 \pm 0.03$ & $0.36 \pm 0.03$ & $0.33 \pm 0.04$ & $0.37 \pm 0.03$ & $0.41 \pm 0.01$ \\
\hline $18: 2 \mathrm{n} 6^{*}$ & $1.09 \pm 0.05$ & $1.04 \pm 0.09$ & $5.59 \pm 0.12$ & $1.43 \pm 0.32^{\mathrm{b}}$ & $1.11 \pm 0.11^{\mathrm{a}}$ & $1.61 \pm 0.30^{\mathrm{b}}$ & $0.98 \pm 0.15^{\mathrm{a}}$ & $3.47 \pm 0.38$ \\
\hline $18: 3 n 3^{*}$ & $0.43 \pm 0.04$ & $0.41 \pm 0.05$ & $1.59 \pm 0.01$ & $0.47 \pm 0.05^{\mathrm{b}}$ & $0.37 \pm 0.05^{\mathrm{a}}$ & $0.50 \pm 0.10^{b}$ & $0.37 \pm 0.06^{\mathrm{a}}$ & $0.90 \pm 0.03$ \\
\hline $20: 0$ & $0.12 \pm 0.01$ & $0.18 \pm 0.04$ & $0.21 \pm 0.00$ & $0.24 \pm 0.05$ & $0.30 \pm 0.04$ & $0.23 \pm 0.03$ & $0.32 \pm 0.07$ & $0.36 \pm 0.01$ \\
\hline 20:1n9 & $1.86 \pm 0.23$ & $1.77 \pm 0.31$ & $6.54 \pm 0.05$ & $0.76 \pm 0.20$ & $0.60 \pm 0.16$ & $0.67 \pm 0.15$ & $0.67 \pm 0.19$ & $10.79 \pm 0.32$ \\
\hline $20: 2 \mathrm{n} 6$ & $0.26 \pm 0.02$ & $0.27 \pm 0.02$ & $0.39 \pm 0.00$ & $0.31 \pm 0.07$ & $0.26 \pm 0.04$ & $0.30 \pm 0.04$ & $0.29 \pm 0.06$ & $0.27 \pm 0.00$ \\
\hline $20: 4 \mathrm{n} 6$ & $2.55 \pm 0.29$ & $2.64 \pm 0.23$ & $0.65 \pm 0.01$ & $3.59 \pm 0.60$ & $3.13 \pm 0.32$ & $3.10 \pm 0.36$ & $3.44 \pm 0.46$ & $0.52 \pm 0.01$ \\
\hline $20: 5 n 3$ & $21.28 \pm 1.05$ & $21.90 \pm 1.29$ & $9.13 \pm 0.08$ & $23.20 \pm 1.33$ & $24.57 \pm 1.19$ & $23.72 \pm 0.95$ & $25.43 \pm 1.14$ & $9.53 \pm 0.21$ \\
\hline $22: 1 \mathrm{n} 11^{*}$ & $1.30 \pm 0.17$ & $1.26 \pm 0.23$ & $8.61 \pm 0.13$ & $0.69 \pm 0.21^{\mathrm{b}}$ & $0.56 \pm 0.23^{\mathrm{ab}}$ & $0.60 \pm 0.19^{\mathrm{ab}}$ & $0.48 \pm 0.14^{\mathrm{a}}$ & $14.81 \pm 0.45$ \\
\hline $22: 5 n 3$ & $0.90 \pm 0.11$ & $0.93 \pm 0.21$ & $2.14 \pm 0.03$ & $1.15 \pm 0.17$ & $1.29 \pm 0.18$ & $1.29 \pm 0.10$ & $1.23 \pm 0.21$ & $1.01 \pm 0.02$ \\
\hline $22: 6 n 3$ & $18.41 \pm 0.76$ & $18.13 \pm 0.73$ & $12.88 \pm 0.16$ & $16.60 \pm 0.95$ & $15.55 \pm 0.99$ & $15.87 \pm 0.81$ & $14.39 \pm 0.90$ & $11.00 \pm 0.24$ \\
\hline 24:1n9 & $0.18 \pm 0.02$ & $0.20 \pm 0.03$ & $0.92 \pm 0.02$ & $0.29 \pm 0.07$ & $0.28 \pm 0.08$ & $0.24 \pm 0.05$ & $0.29 \pm 0.11$ & $0.96 \pm 0.01$ \\
\hline Total n3 & $41.59 \pm 2.03$ & $41.91 \pm 1.08$ & $26.04 \pm 0.25$ & $42.09 \pm 1.47$ & $42.63 \pm 0.89$ & $42.15 \pm 0.85$ & $42.07 \pm 1.16$ & $22.74 \pm 0.38$ \\
\hline Total n6 & $4.14 \pm 0.40$ & $4.19 \pm 0.24$ & $6.72 \pm 0.12$ & $5.72 \pm 0.74$ & $4.91 \pm 0.40$ & $5.37 \pm 0.32$ & $5.21 \pm 0.54$ & $4.37 \pm 0.39$ \\
\hline n3:n6 ratio* & $10.05 \pm 5.06$ & $10.02 \pm 0.55$ & $3.87 \pm 0.10$ & $7.48 \pm 0.98^{\mathrm{a}}$ & $8.75 \pm 0.77^{c}$ & $7.86 \pm 0.53^{\mathrm{ab}}$ & $8.16 \pm 0.95^{b c}$ & $5.23 \pm 0.48$ \\
\hline $\begin{array}{l}\text { Total FA* } \\
\left(\mathrm{mg} \mathrm{g}^{-1}\right)\end{array}$ & $6.7 \pm 0.3^{\mathrm{a}}$ & $7.1 \pm 0.3^{b}$ & $198.2 \pm 8.4$ & $5.3 \pm 0.6^{\mathrm{a}}$ & $5.8 \pm 0.4^{\mathrm{b}}$ & $6.1 \pm 0.5^{\mathrm{c}}$ & $5.6 \pm 0.6^{\mathrm{ab}}$ & $226.0 \pm 14.6$ \\
\hline
\end{tabular}




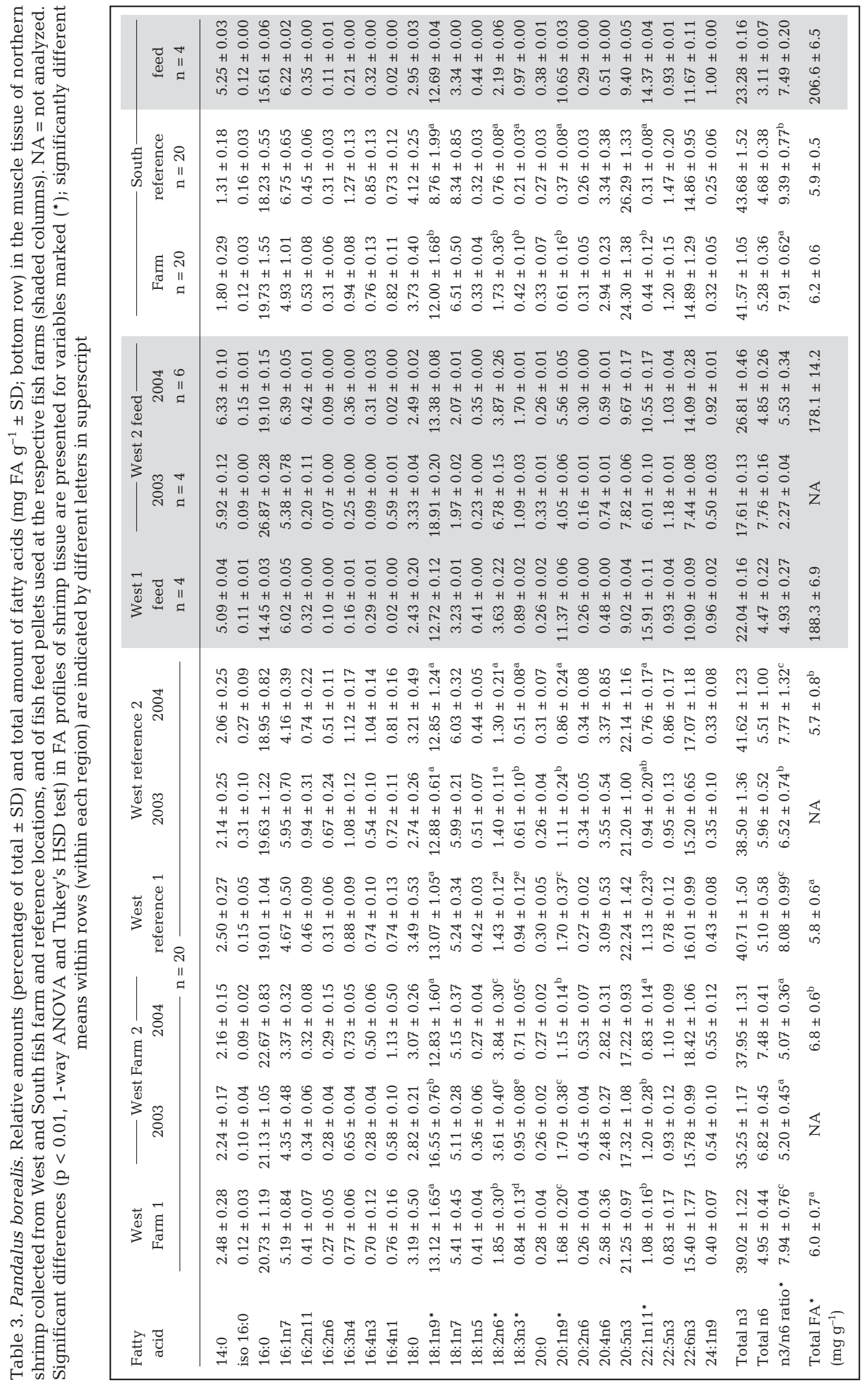




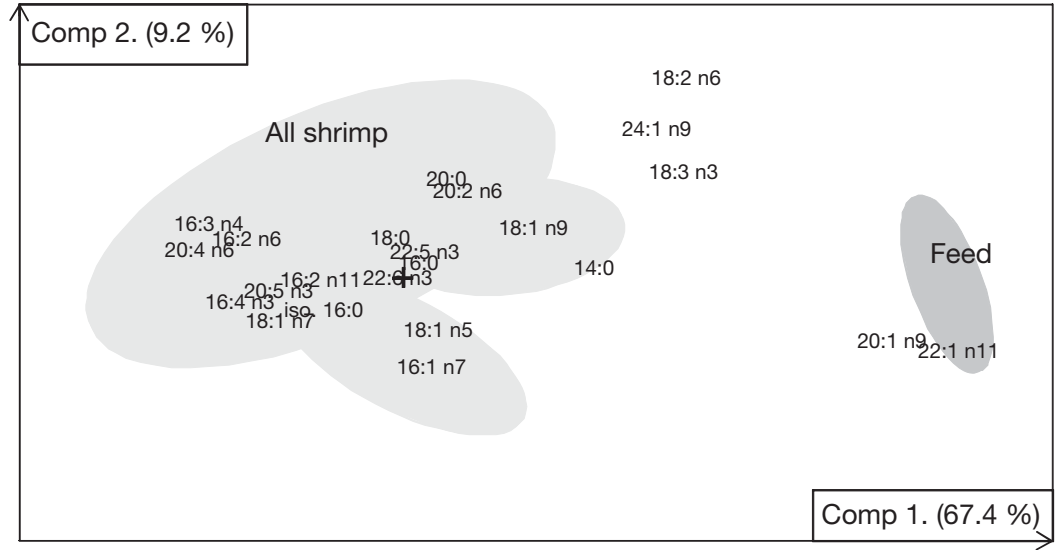

Fig. 2. Pandalus borealis. Principal component biplot of the distribution of fatty acids for all shrimp together with all the salmon feed pellet samples. (+): center of the plot

whereas the values are between 4 and $16 \%$ in the pellets.

The composition of FAs in the shrimp tissue was, however, not uniform among reference or fish farm stations (Fig. 3). While shrimp collected at W-ref2 during the 2 consecutive years were not distinguished by the 24 FAs, the shrimp from the other stations were distinctly different. The regions were treated separately as ANOVA showed significant differences between the farms and the reference samples.

In the north area the difference between NF shrimp and North ref (N-ref) shrimp was not significant (Fig. 4, ANOSIM: $\mathrm{R}=0.09$ ). None of the tracer FAs in shrimp were significantly different between the 2 locations, nor was the n3:n6 ratio different, and the reference shrimp had a higher total FA content (Table 2).

In the middle area there was a clear distinction between the Middle ref (Mref) shrimp and the MF1 and MF3 shrimp (Fig. 5, ANOSIM: $\mathrm{R}=0.58$ and 0.63 , respectively). Significantly higher levels of FAs 18:2n6 and 18:3n3 were detected in shrimp at both middle farm locations and this contributed the most to the differences (Table 2, Fig. 5), together with the higher level of 22:1n11 in shrimp from MF1. The shrimp from the MF2 had an overlapping distribution between the reference and the 2 farm locations (Fig. 5, ANOSIM: $\mathrm{R}=0.49,0.42$ and 0.35 , respectively). A significantly lower $\mathrm{n} 3: \mathrm{n} 6$ ratio was detected in shrimp from MF1 and higher total FA content was detected in shrimp from MF3, compared with shrimp from M-ref (Table 2).

In the west the WF shrimp were clearly distinguished from the W-ref shrimp (Fig. 6). Although WF1 was partly overlapping W-ref1 (Fig. 6, ANOSIM: $R=0.26$ ), there was a clear separation of the other reference locations (ANOSIM: $\mathrm{R}=0.71$ and $0.83)$. For WF2, the dissimilarity to $\mathrm{W}$-ref was between $\mathrm{R}=0.97$ and $\mathrm{R}=1$. The 18:2n6 FA contributed most to the differences between farm and reference shrimp, and a significantly higher level was evident at both farm locations (Table 3). Also

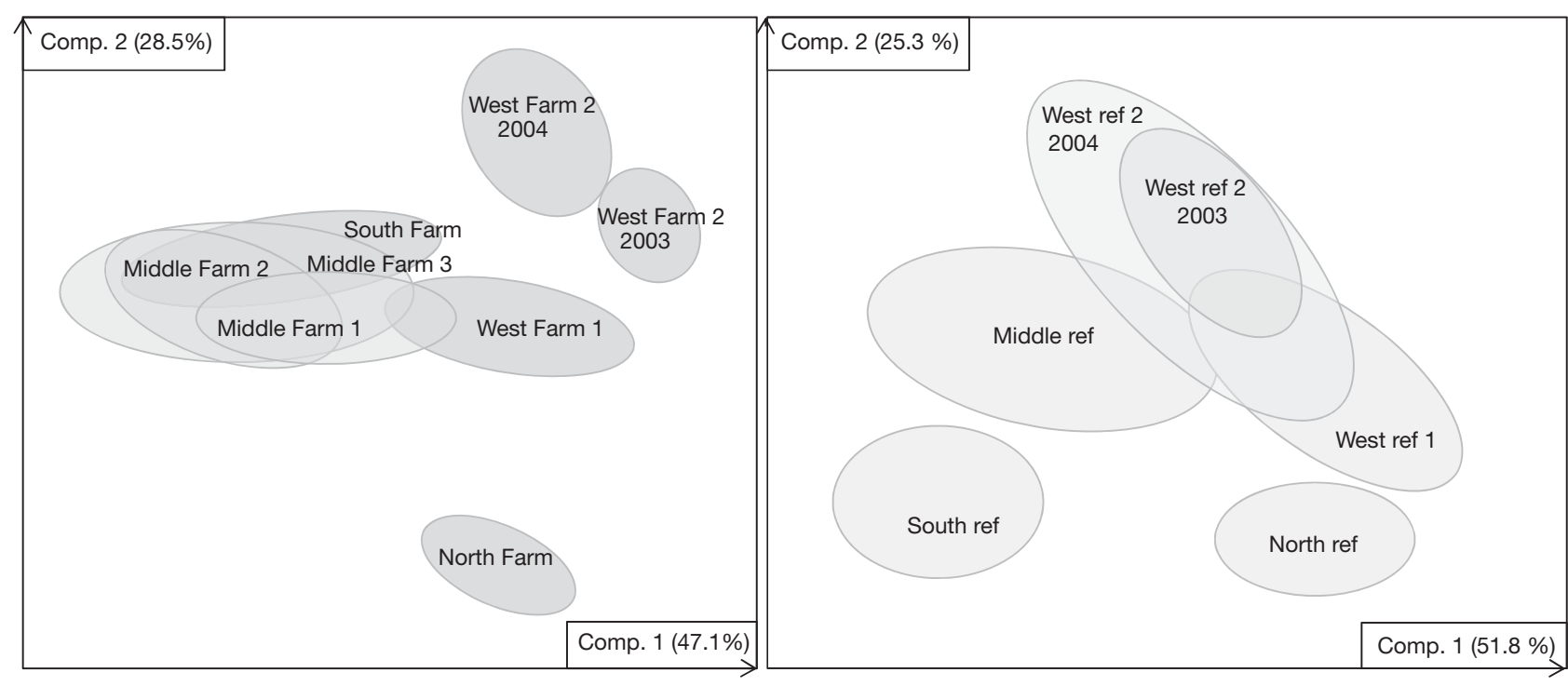

Fig. 3. Pandalus borealis. Principal component biplots showing the distribution of fatty acids for shrimp from all farm locations (left) and all reference locations (right). Actual fatty acids are not shown. See Fig. 1 and Table 1 for abbreviations and locations of sites 


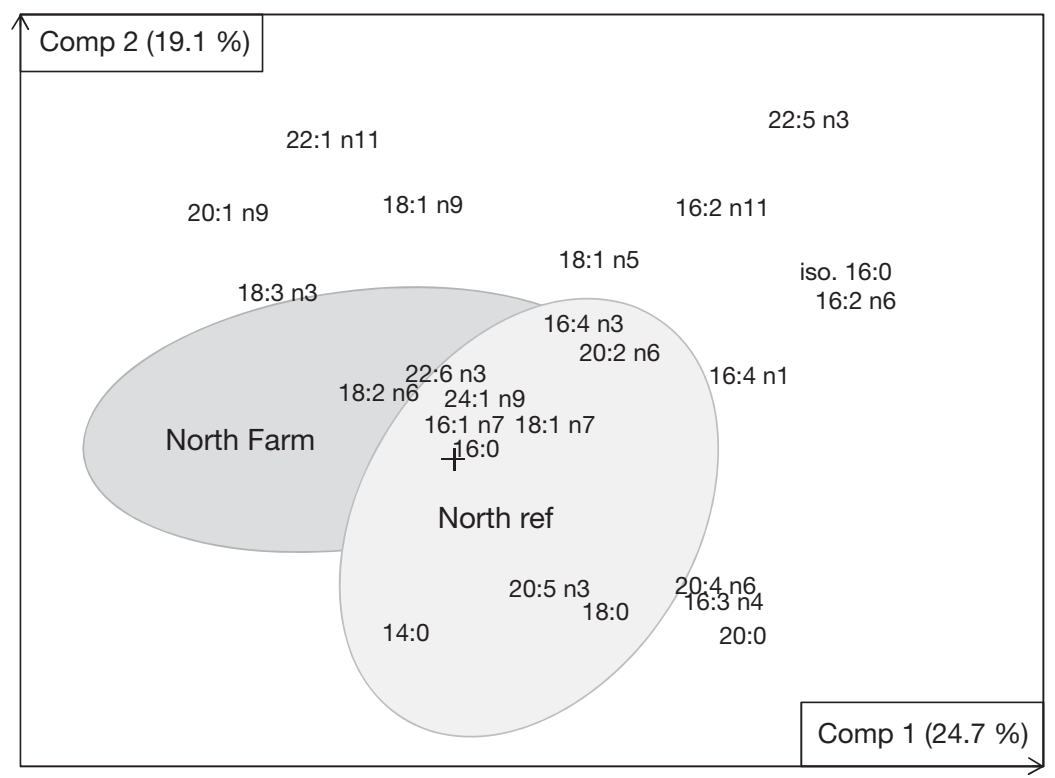

Fig. 4. Pandalus borealis. Principal component biplot of the distribution of fatty acids for shrimpfrom North Farm and North reference (ref) sites. (+): center of the plot

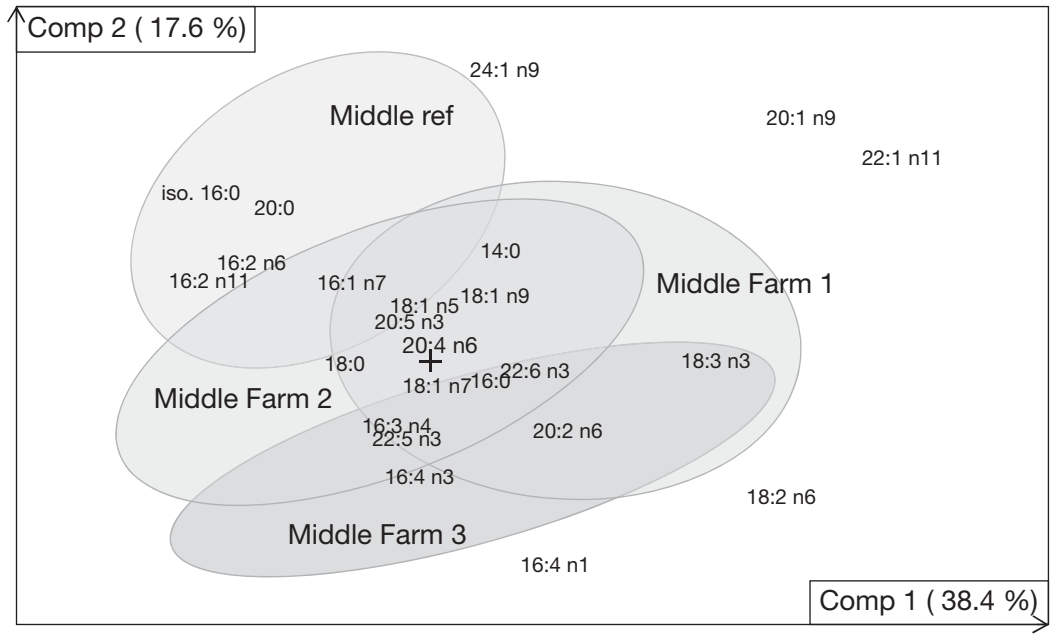

Fig. 5. Pandalus borealis. Principal component biplot of the distribution of fatty acids for shrimp from Middle Farm 1, 2 and 3 and Middle reference (ref) sites. $(+)$ : center of the plot

FAs $18: 3 \mathrm{n} 3,20: 1 \mathrm{n} 9$ and $22: 1 \mathrm{n} 11$ were important for the separation of locations and found in significantly higher amounts in most farm samples (Table 3). The WF2 shrimp had a 17 to $19 \%$ higher total FA content than the reference samples, which was significant, as well as a lower $n 3: n 6$ ratio (Table 3). The farm locations were completely separated along the second $\mathrm{PC}$, and significant differences were present among them in all tracer FAs, except 18:2n6 (Table 3). However, these differences did not affect the distinct farm versus reference separation present along the first PC (Table 3, Fig. 6).
In the south the SF shrimp were clearly different from the reference (Sref) shrimp (Fig. 7, ANOSIM: $\mathrm{R}=0.8$ ). A significantly higher level of all tracer FAs and a lower n3:n6 ratio were detected in the farm shrimp (Table 3). FAs 18:2n6 and 18:3n3 contributed most to the difference (Fig. 7).

\section{DISCUSSION}

The results of this study demonstrated that Northern shrimp can incorporate fatty acids of fish farm waste origin into its tissues, suggesting that the release of aquaculture derived wastes into the environment can influence the benthic food web of the recipient environment. Analyses of muscular tissue FA compositions demonstrated that shrimp collected close to fish farms had a higher composition of tracer FAs than did the muscular tissue of individuals collected from reference locations.

Fish oil from herring Clupea harengus and other 'northern hemisphere' fish species used in salmon feeds are rich in FAs 20:1n9 and 22:1n11 (Bell et al. 2003), and studies have demonstrated elevated levels of these marine FAs in sediments in the recipient zone of the fish farms (Johnsen et al. 1993, Henderson et al. 1997). In addition to these marine FAs, Kutti et al. (2007a) also found higher levels of 18:2n6 and a total FA content that was 10 times higher in fish farming sediments compared with the reference location. Modifications of tissue FA composition have been reported in saithe Pollachius virens collected in Norwegian fjords with fish farms (Skog et al. 2003) and in aggregating saithe and cod Gadus morhua close to fish farm cages (Fernandez-Jover et al. 2011). In particular, FA 18:2n6 proved to be a suitable tracer in these gadoids, and an increase in body condition as well as a decreased n $3: n 6$ ratio in farmed fish compared with fish from reference locations were good indicators. Elevated levels of FA 18:2n6 and depletion of the n3:n6 ratio have also been used as factors in authenticating studies of wild versus farmed fish (Molkentin et al. 2007, Busetto et al. 


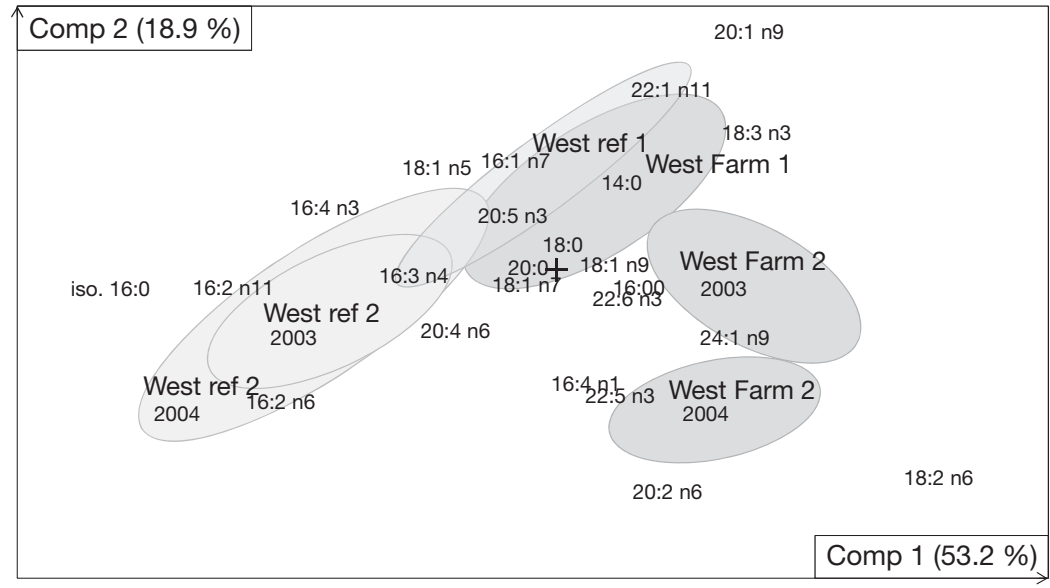

Fig. 6. Pandalus borealis. Principal component biplot of the distribution of fatty acids for shrimp from West Farm 1 and 2 and West reference (ref) 1 and 2 sites. Sampling from West Farm 2 and West ref 2 were conducted in both 2003 and 2004. (+): center of the plot

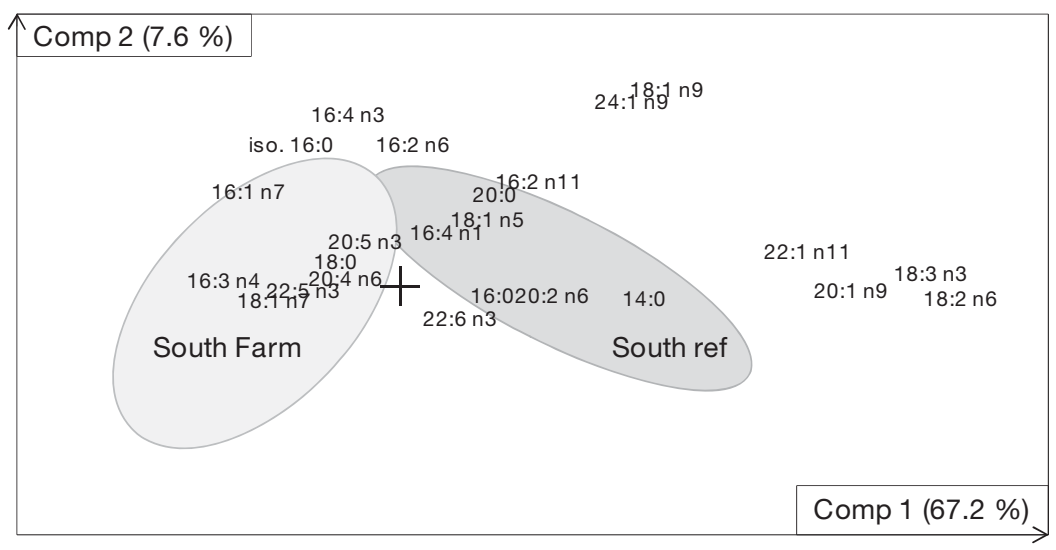

Fig. 7. Pandalus borealis. Principal component biplot of the distribution of fatty acids for shrimp from South Farm and South reference (ref) sites. (+): center of the plot

2008), as well as in assimilation studies on blue mussels Mytilus edulis fed salmon feed (Redmond et al. 2010).

Shrimp are an important link between the benthic and higher trophic levels (Shumway et al. 1985), and the documentation of the shift in FAs between shrimp collected at farming locations compared with reference locations has provided a greater insight into the effect of fish farming on the local benthic food web. The general FA profile of the reference shrimp in these investigations resembled the profiles reported earlier by Ackman \& Eaton (1967) and Hopkins et al. (1993). The FA composition in shrimp and the changes that occurred when experimentally influenced by farm-originated matter was thoroughly described by Olsen et al. (2009). Shrimp were fed salmon feed pellets and had a sudden response to the feed. Not only were the levels of FA 18:2n6 elevated in muscle tissue, but FAs 18:3n3, 20:1n9 and 22:1n11 were also present after $11 \mathrm{~d}_{i}$ thus, they were suggested for use as tracer FAs for organic fish farm waste in shrimp, as the levels in tissues rose in response to the increased dietary level (Olsen et al. 2009). In this present field study, the same 4 FAs were, in various degrees, the most important ones to separate shrimp from their farm and reference locations and as such provide validation that these FAs are useful tracers for tracking fish farm waste in shrimp. In particular, FA 18:2n6 has proved suitable after this field study, because it has the largest degree of modification and is the most important FA that separates farm and reference locations. This corresponds to the findings in fish (Skog et al. 2003, FernandezJover et al. 2007, 2011) and zooplankton (Fernandez-Jover et al. 2009).

In general, the farm locations in this study were well established and had a biomass between 450 and $2400 \mathrm{t}$ at the time of sampling. Apart from NF and MF2, the food consumption at the farms was between 3.6 and $9.5 \mathrm{t} \mathrm{d}^{-1}$, which gives a potential of 0.7 to $3 \mathrm{t} \mathrm{d}^{-1}$ of organic waste, which is distributed to the recipient environment (as estimated by considering a $2 \%$ feed loss and 20 to $30 \%$ released faecal waste). Although incidents of large feed spills do occur, uneaten feeds constitute a minor part of the organic waste from a farm and the rest is faeces. There is, however, a similarity in the tracer FA composition between faeces and salmon feed pellets (Johnsen et al. 2000), and thus, the FA tracers will not indicate whether shrimp have consumed feeds or faeces. The feed composition can differ substantially over time because prices, availability and seasonal variation in the fisheries influence the supply of ingredients. This was apparent at WF2, where feeds sampled twice within a few months were different (Table 3). Although this resulted in a full separation between the 2 consequent shrimp samplings (Fig. 6), the differences were along the second PC axis and were minor compared with the differences along the first PC axis that completely separated WF2 shrimp from the reference shrimp. 
Owing to the potential risk of damaging mooring lines and trawls, sampling was conducted at relatively large distances from the farms, which could diminish the signals of tracer FAs in the shrimp. However, model simulations (Stigebrandt et al. 2004) have shown an extensive distribution of fish farm waste, and Kutti et al. (2007a) found traces of both FA and stable isotope markers typical of fish farm matter in sediment traps as far as $550 \mathrm{~m}$ from a farm. They also found isotope traces at a $900 \mathrm{~m}$ distance from the farm (no FA analyses conducted), which indicated a distribution range for fish farm waste. Shrimp sampling was done with long trawl hauls that usually ended 400 to $800 \mathrm{~m}$ away from the farms, which was within this distribution range. In the present study, the trawling at NF and MF2 was conducted at a greater distance from the farm. The results showed no significant modifications in FA composition between the NF and N-ref locations, and MF2 was distributed between the farm and reference samples. This confirms that the distance was too great and that a more defined sampling should be performed in future investigations. S-ref was sampled $165 \mathrm{~km}$ from the farm location, and we lacked a local reference comparison for the farm samples. However, the FA composition of the SF shrimp had the same patterns as the WF, MF1 and MF2 samples, and we are confident that this was a response to a diet originating from fish farm waste.

At WF2 the construction design made it possible to trawl in the actual 'footprint' of the farm, and here the strongest signals in both FA modifications and total FA content were found (Fig. 6, Table 3). The shrimp from WF2 had the same content of FAs 18:2n6, 18:3n3 and 22:1n11 as did the shrimp that had been directly feeding on salmon feed pellets for almost 3 mo (Olsen et al. 2009). Shrimp muscle tissue is lean, with a total FA content of 3 to $5 \mathrm{mg} \mathrm{g}^{-1}$. The shrimp from WF2 and MF3 had a significant increase in the total FA content; they were close to $20 \%$ fatter than their respective reference shrimp. The WF2 shrimp had the same total FA content as shrimp from the feeding experiment (Olsen et al. 2009), almost $7 \mathrm{mg} \mathrm{g}^{-1}$ (Table 3 ). Fish aggregated at a farm tend to have alterations in body condition (Dempster et al. 2011, Fernandez-Jover et al. 2007) and FA composition (Fernandez-Jover et al. 2007, 2011), and our results indicate the same for shrimp. However, we have no knowledge on whether shrimp have ingested organic waste directly through faeces or feed pellets, or indirectly by feeding on influenced infauna that have had this diet. Nor do we have information on how the altered FA composition may influ- ence shrimp physiology and ecology. The WF2 site was thoroughly investigated by Kutti et al. (2007 a,b), and they found 35- and 10-fold increases in infauna biomass and abundance, respectively. They also found a sedimentation rate of organic carbon $250 \mathrm{~m}$ away from the farm that was 9 times higher than the reference site, but no elevated content in the sediments, owing to dispersion and fauna decomposition. Shrimp are demersal opportunistic omnivores, and sedimentation models (Ramseier et al. 2000) have confirmed that their distribution is correlated with the moderate to high $(>1.5 \%)$ sediment organic carbon content (Wigley 1960, Haynes \& Wigley 1969). The sediment condition close to a fish farm may therefore be suitable for shrimp, and if the shrimp use farm waste directly, they may help prevent the overloading of the locality through decomposition, which is documented for infauna (Kutti et al. 2007a).

Our results show that shrimp close to fish farms can incorporate organic fish farm waste into their diet, either directly through waste feed and faeces or indirectly by feeding on influenced infauna. The alterations in shrimp tissue FA composition were significant, proving that shrimp can be used as a suitable indicator species for monitoring purposes. Fish farm waste may represent a persistent food source for other trophic levels in the benthic food in the vicinity of the farm, as has been described for infauna (Kutti et al. 2007b) and wild fish (Dempster et al. 2009).

Acknowledgements. We thank the Norwegian Research Council for funding this project, which is a part of the CANO project (Carrying Capacity in Norwegian aquaculture). We also thank the fishers who contributed by collecting the shrimp and the respective fish farmers and staff for cooperation throughout the planning and sampling. We also thank R. Bannister at the Institute of Marine Research for guidance through statistical improvements and by improving the language.

\section{LITERATURE CITED}

Ackman RG, Eaton CA (1967) Fatty acid composition of the decapod shrimp, Pandalus borealis, in relation to that of the euphasid, Meganyctiphanes norvegica. J Fish Res Board Can 24:467-471

Anonymous (2009) Strategy for an environmentally sustainable Norwegian aquaculture industry. Doc L-0535 B. Norwegian Ministry of Fisheries and Coastal Affairs, Oslo

Bell JG, Henderson RJ, Tocher DR, McGhee F and others (2002) Substituting fish oil with crude palm oil in the diet of Atlantic salmon (Salmo salar) affects muscle fatty acid composition and hepatic fatty acid metabolism. J Nutr 132:222-230

Bell JG, Tocher DR, Henderson RJ, Dick JR, Crampton VO (2003) Altered fatty acid compositions in Atlantic salmon 
(Salmo salar) fed diets containing linseed and rapeseed oils can be partially restored by a subsequent fish oil finishing diet. J Nutr 133:2793-2801

Bergström BI (2000) The biology of Pandalus. In: Southward AJ, Tyler PA, Young CM, Fuiman L (eds) Advances in Marine Biology, Vol 38. Academic Press, London, p 55-245

Blanchet C, Lucas M, Julien P, Morin R, Gingras S, Dewailly E (2005) Fatty acid composition of wild and farmed Atlantic salmon (Salmo salar) and rainbow trout (Oncorhynchus mykiss). Lipids 40:529-531

$>$ Brown JR, Gowen RJ, McLusky DS (1987) The effect of salmon farming on the benthos of a Scottish sea loch. J Exp Mar Biol Ecol 109:39-51

Bureau DP, Gunther SJ, Cho CY (2003) Chemical composition and preliminary theoretical estimates of waste outputs of rainbow trout reared in commercial cage culture operations in Ontario. N Am J Aquac 65:33-38

> Busetto ML, Moretti VM, Moreno-Rojas JM, Caprino F and others (2008) Authentication of farmed and wild turbot (Psetta maxima) by fatty acid and isotopic analyses combined with chemometrics. J Agric Food Chem 56: 2742-2750

> Carss DN (1990) Concentrations of wild and escaped fishes immediately adjacent to fish farm cages. Aquaculture 90: $29-40$

> Cho CY, Bureau DP (1998) Development of bioenergetic models and the Fish-PrFEQ software to estimate production, feeding ration and waste output in aquaculture. Aquat Living Resour 11:199-210

> Dempster T, Uglem I, Sanchez-Jerez P, Fernandez-Jover D, Bayle-Sempere J, Nilsen R, Bjorn PA (2009) Coastal salmon farms attract large and persistent aggregations of wild fish: an ecosystem effect. Mar Ecol Prog Ser 385: $1-14$

Dempster T, Sanchez-Jerez P, Fernandez-Jover D, BayleSempere J, Nilsen R, Bjorn PA, Uglem I (2011) Proxy measures of fitness suggest coastal fish farms can act as population sources and not ecological traps for wild gadoid fish. PLoS ONE 6:e15646

FAO (Food and Agriculture Organization of the United Nations) (2010) The state of the world fisheries and aquaculture 2010. FAO, Rome

Fernandez-Jover D, Jimenez JAL, Sanchez-Jerez P, BayleSempere J, Casalduero FG, Lopez FJM, Dempster T (2007) Changes in body condition and fatty acid composition of wild Mediterranean horse mackerel (Trachurus mediterraneus, Steindachner, 1868) associated to sea cage fish farms. Mar Environ Res 63:1-18

Fernandez-Jover D, Sanchez-Jerez P, Bayle-Sempere JT, Arechavala-Lopez P, Martinez-Rubio L, Jimenez JAL, Lopez FJM (2009) Coastal fish farms are settlement sites for juvenile fish. Mar Environ Res 68:89-96

Fernandez-Jover D, Martinez-Rubio L, Sanchez-Jerez P, Bayle-Sempere JT and others (2011) Waste feed from coastal fish farms: a trophic subsidy with compositional side-effects for wild gadoids. Estuar Coast Mar Sci 91: 559-568

Gunstone F, Harwood J, Padley F (1994) The lipid handbook. Chapman \& Hall, London

$>$ Haynes EB, Wigley RL (1969) Biology of the northern shrimp Pandalus borealis in the Gulf of Maine. Trans Am Fish Soc 98:60-76

Henderson RJ, Forrest DAM, Black KD, Park MT (1997) The lipid composition of sealoch sediments underlying salmon cages. Aquaculture 158:69-83

Hopkins CCE, Sargent JR, Nilssen EM (1993) Total lipid content, and lipid and fatty-acid composition of the deepwater prawn Pandalus borealis from Balsfjord, northern Norway: growth and feeding relationships. Mar Ecol Prog Ser 96:217-228

Johnsen RI, Grahl-Nielsen O, Lunestad BT (1993) Environmental distribution of organic waste from a marine fish farm. Aquaculture 118:229-244

Johnsen RI, Grahl-Nielsen O, Roem A (2000) Relative absorption of fatty acids by Atlantic salmon (Salmo salar) from different diets, as evaluated by multivariate statistics. Aquac Nutr 6:255-261

Kutti T, Ervik A, Hansen PK (2007a) Effects of organic effluents from a salmon farm on a fjord system. I. Vertical export and dispersal processes. Aquaculture 262: 367-381

Kutti T, Hansen PK, Ervik A, Høisæther T, Johannessen PJ (2007b) Effects of organic effluents from a salmon farm on a fjord system. II. Temporal and spatial patterns in infauna community composition. Aquaculture 262: 355-366

Kvalheim O, Karstang TV (1987) A general-purpose program for multivariate data analysis. Chemom Intell Lab Syst 2:235-237

Molkentin J, Meisel H, Lehmann I, Rehbein H (2007) Identification of organically farmed Atlantic salmon by analysis of stable isotopes and fatty acids. Eur Food Res Technol 224:535-543

NDF (Norwegian Directorate of Fisheries) (2008) Economic and biological key figures. NDF, Bergen. www.fiskeridir. no/english/statistics/norwegian-fisheries/economic-andbiological-key-figures

NDF (Norwegian Directorate of Fisheries) (2010) Norwegian aquaculture statistics. NDF, Bergen. www.fiskeridir.no/ english/statistics/norwegian-aquaculture/aquaculturestatistics

> Olsen SA, Ervik A, Grahl-Nielsen O (2009) Deep-water shrimp (Pandalus borealis, Krøyer 1838) as indicator organism for fish-farm waste. J Exp Mar Biol Ecol 381: 82-89

Øverland M, Sørensen M, Storebakken T, Penn M, Krogdahl A, Skrede A (2009) Pea protein concentrate substituting fish meal or soybean meal in diets for Atlantic salmon (Salmo salar) - effect on growth performance, nutrient digestibility, carcass composition, gut health, and physical feed quality. Aquaculture 288:305-311

Parsons DG (2005) Predators of northern shrimp, Pandalus borealis (Pandalidae), throughout the North Atlantic. Mar Biol Res 1:48-58

Pearson TH (1980) Macrobenthos of fjords. In: Freeland HJ, Farmer DM, Levings CD (eds) Fjord oceanography. NATO Conf Ser 4 Mar Sci.Plenum Press, New York, NY, p 569-602

Quinn GP, Keough MJ (2002) Experimental design and data analysis for biologists. Cambridge University Press, Cambridge

Ramseier RO, Garrity C, Parsons DG, Koeller P (2000) Influence of particulate organic carbon sedimentation within the seasonal sea-ice regime on the catch distribution of northern shrimp (Pandalus borealis). J Northwest Atl Fish Sci 27:35-44

Redmond KJ, Magnesen T, Hansen PK, Strand O, Meier S (2010) Stable isotopes and fatty acids as tracers of the assimilation of salmon fish feed in blue mussels (Mytilus 
edulis). Aquaculture 298:202-210

Samuelsen OB, Ervik A, Solheim E (1988) A qualitative and quantitative analysis of the sediment gas and diethylether extract of the sediment from salmon farms. Aquaculture 74:277-285

Shumway SE, Perkins HC, Schick DF, Stickney AP (1985) Synopsis of biological data of the pink shrimp Pandalus borealis (Krøyer 1838). FAO Fisheries Synopsis 144. NOAA Tech Rep NMF 30. FAO, Rome

Skog TE, Hylland K, Torstensen BE, Berntssen MHG (2003) Salmon farming affects the fatty acid composition and taste of wild saithe Pollachius virens L. Aquac Res 34

Editorial responsibility: Pablo Sánchez-Jerez, Alicante, Spain

$$
\text { 999-1007 }
$$

Skretting Norway (2010) Miljørapport 2010, social and environmental report 2010. Skretting Norway, Stavanger. www.skretting.no

Stigebrandt A, Aure J, Ervik A, Hansen PK (2004) Regulating the local environmental impact of intensive marine fish farming: III. A model for estimation of the holding capacity in the modelling-ongrowing fish farm-monitoring system. Aquaculture 234:239-261

Wigley RL (1960) Note on the distribution of Pandalidae (Crustacea, Decapoda) in New England waters. Ecology 41:564-570

Submitted: June 27, 2011; Accepted: December 19, 2011

Proofs received from author(s): January 30, 2012 